\title{
Optimization of the Gasoline Production Plant in order to Increase Feed
}

\author{
Amir Samimi ${ }^{*}$, Kasra Kavosi², Soroush Zarinabadi ${ }^{3}$, Alireza Bozorgian ${ }^{1}$ \\ ${ }^{1}$ Department of Chemical Engineering, Mahshahr Branch, Islamic Azad University, Mahshahr, Iran \\ ${ }^{2}$ Head of Refining Process Engineering of Catalytic Units, Oil Refinery Company \\ ${ }^{3}$ Department of Engineering, Ahvaz Branch, Islamic Azad University, Ahvaz, Iran
}

\section{ART ICLE INFO}

\section{Article history:}

Submitted: 2019-07-17

Revised: 2019-10-30

Accepted: 2019-12-01

Available online:2019-12-20

Manuscript ID: PCBR-1911-1069

\section{G RAPH I C A L A B S T RACT}

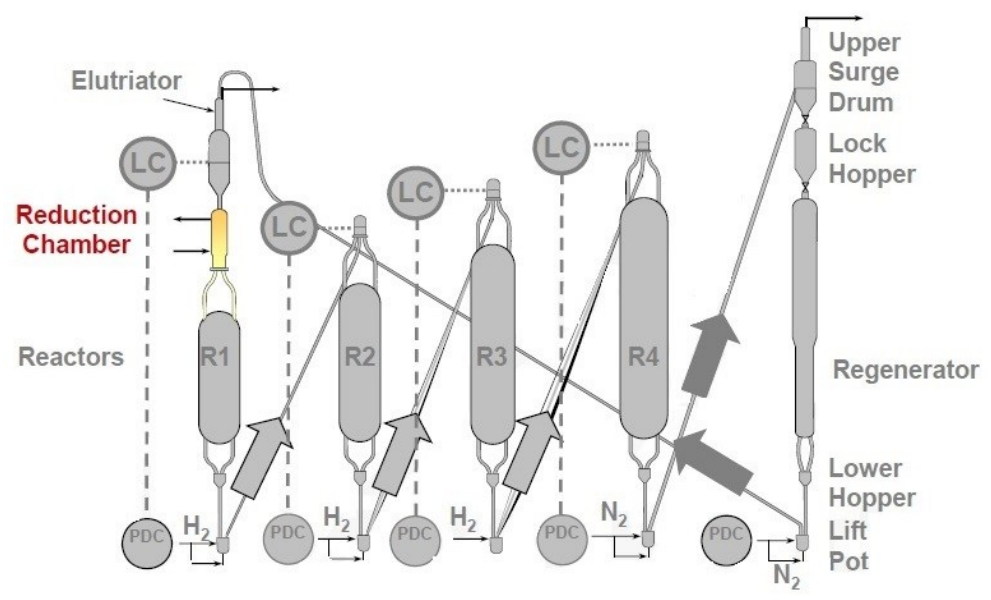

\begin{tabular}{l} 
K E Y W O R D S \\
\hline Catalyst \\
Circulating gas \\
Coke \\
Green oil \\
Stabilizer \\
\hline
\end{tabular}

\begin{abstract}
A B S T R A C T
One of the most important process in refineries is Naphtha catalytic conversion. In this process, gasoline with high octane number produce in the petrochemical complexes of precious aromatics such as benzene and toluene. Increasing the capacity of Gasoline Production Plant (G.P.P) will cause problems such as the increase of pressure downfall, reduction of output pressure of circulating gas compressor, increasing the thermal load of the re-boiler furnaces of unit towers, increase of the eventuality of formation green oil in vessels, increase of the eventuality of coke formation on the catalyst and eventually reducing the catalyst life span. In this research, operating conditions have been investigated that indicates the increase of the petrochemical feed with the design capacity of 71,000 barrels per day, to the 75,000 barrels per day in north hemisphere. The results indicate that with increasing feed, the entrance temperature and pressure to the unit reactor should be increased. According to the obtained results the best temperature (in Feed) is $525^{\circ} \mathrm{C}$, output pressure of circulating gas compressor is more than $22 \mathrm{ton} / \mathrm{hr}$ and the circulation of catalysis range is $750-950 \mathrm{~kg} / \mathrm{hr}$, the Octane Number will be a Constant Rate 95 and the amount of Coke Formation in all Conditions 3.5-4.3\%. The outcomes also show how this approach can be used to gain insight into some refineries and how to deliver results in a comprehensible and user-friendly way.
\end{abstract}




\section{Introduction}

The dependence of advanced countries on petroleum products, especially gasoline and the outbreak of petroleum crises in the 1970s due to the increasing and overcoming consumption on production and extraordinary rise in petroleum prices and its products, urged industrialized countries to deal with energy problem and take a different approach. Undoubtedly, the importance of the strategic product, gasoline in terms of current conditions, quality and quantity dimensions is not covered on everyone with respect to the growing demand of the country and the growth of imports and further dependence and the spread of environmental pollution and the prevalence of various diseases caused by pollution and the low quality of existence gasoline. One of the most important properties and quality features of a high quality gasoline product is also low levels of pollutants such as sulfur, benzene, and aromatic compounds such as sulfur, benzene, and aromatic compounds and lead and manganese particles from environmental standards, octane number of the fuel. The higher the octane number is, the fuel is more resistant to combustion, pressure and heat. Basically, the octane number is a measure to indicate the gasoline resistance to the heat, push and start of spontaneous combustion (no spark).

The octane number is a fully conventional quantity of terms that have assumed the normal octane number of heptane, zero and the iso-octane 95, and the rest of the compounds have been calculated to these two [1]]. In the case of hydrocarbons, they are paraffinic the higher the number of branches increases, the higher the octane number increases. Being cyclic. Also increases the octane number.

Regarding the mentioned cases, it is obvious that the conversion of normal paraffin hydrocarbons to iso paraffin's, naphthenes and aromatics leads to an increase in the octane number. As we know, the ignition of gasoline in the engine must be so that it does not strike or beat slowly. The engine will be beat when the fuel and air mixture, which is a high ignition material due to congestion, will be affected sooner than the spark. Because before the piston reaches its highest point in the middle of the road and with an opposing force it goes down, it can cause serious damage to the parts of the engine. After another aspect, it can be said that the ability to compress the fuel before spontaneous combustion is the octane number, and the numerical scale is an agreement showing the burn of a fuel [2]].

The importance of the octane rating parameter of gasoline is that one way to increase the output power of the car's engine is to increase their concentration ratio, but this is achieved only by increasing the strength of gasoline resistance to spontaneous combustion, which is the same concept of the octane number. The fast burning petrol has caused a shock to reduce the efficiency and output power of the engine and can cause serious physical damage to parts of the engine [ $\underline{3}]$.

In 2019, Samimi et al wrote one article about for four factors knowledge in Catalytic Reforming Units (CRU). Density, pH, S.FE and $\mathrm{H}_{2} \mathrm{~S}$. According to the obtained results the best range of density (in Feed) is less than $0.515 \mathrm{~kg} / \mathrm{m}^{3}, \mathrm{pH}$ (water in vessels) is more than 6.7, Sulphides FE (S.FE) is less than 1.5 ppm and $\mathrm{H}_{2} \mathrm{~S}$ in recycle gas is less than $700 \mathrm{ppm}$. 
In 2019 Zarinabadi et al wrote the article about the catalytic conversion of naphtha is a refinery process in which heavy naphtha feeds through the catalytic bed of several reactors at high temperatures and pressures increase the aromatics content of naphtha and ultimately increase its octane number. In this study, Operational Conditions in Octanizer and Hydro-treating Units in Oil Refinery Company is investigated and optimized the conditions of catalysis was investigated.

In this research, operating conditions have been investigated that indicates the increase of the petrochemical feed with the design capacity of 71,000 barrels per day, to the 75,000 barrels per day.

\section{Data collection and classification}

Data collection and storage technologies have made it possible for organizations to extract a large amount of data in the shortest possible time. The exploitation of this stored data, in order to extract useful and practical information, is the general purpose of the public activity known as data mining. Data mining the process of discovery and analysis, either automatically or semi-automatic, is of greatly high value in order to discover meaningful patterns and rules [4]].

Data mining is an interdisciplinary branch of computer science that involves the discovery of patterns from a large set of data. The purpose of this advanced analysis process is to extract information from a dataset and turn it into an understandable structure for later use. The methods used are a combination of artificial intelligence, machine learning, statistics, and database systems and business intelligence [్].These data are also challenging issue.

\section{The description of the gasoline production process Naphtha hydro treating Unit (NHT):}

The process with the returned gas should be used in the process of naphtha purification because the amount of sulfur is high in the feed (700-1200 wt ppm) [6]. Of course, in this mood, the gas may be washed with the amine. The existent sulfur and nitrogen in the feed are converted to $\mathrm{H}_{2} \mathrm{~S}$ and $\mathrm{NH}_{3}$ after passing through the catalyst bed and in the hydrogen adjacency. The naphtha purification unit is designed for a certain rate of feed along with the highest level of sulfur, nitrogen, mercury, arsenic and other materials in the petroleum. If the quality of the feed changes due to the change in the quality of the processed petroleum and the higher rate of sulfur and nitrogen enters into the system, it is necessary the beneficiary increases the entrance temperature of the reactor. For the new petroleum, the obtained naphtha feed from it should be tested in terms of all impurities, including metals [7]. If possible, this doing should be done before the injection of the feed into the unit, but otherwise, it is necessary to be done as soon as possible. This work prevents the fast saturating of the catalyst due to the entry of more metals. The feed with higher boiling point doesn't specifically affect the performance of the catalyst ( 20 ${ }^{\circ} \mathrm{C}$ ) except that it is causing more coke to sit on the catalyst and shorten its life span. After mixing with fresh hydrogen and the returned hydrogen (a purity of about 90 volume percent) and passing through the thermal exchanger and furnace, the process feed (heavy naphtha) temperature increased to ranges 
from 260 to $320{ }^{\circ} \mathrm{C}$ (the amount of temperature depends on the catalyst lifetime or the intensity of desulphurization). The heated feed enters into the catalytic reactor after passing through the furnace. The reactor product enters into separator with highpressure after the thermal exchange with the entrance feed as well as chilling by the aerial cooler and increasing a certain amount of supplementary hydrogen. Hydrogen along with light gases and hydrogen sulfide is exited from the upper part of the separator.

The major part of this gas is returned to entrance feed in the processes that are operating with the returned gas system. The output liquid from the separator also enters the stripper tower. The condenser of this tower is the total reflux type. Ultimately, the light gases and remaining sulfur are exiting as hydrogen sulfide gas from above the tower. The refined product is also exited after the exchange of heat with the entrance feed with water contents of less than 1 , the weighted ppm and sulfurous and nitrogenous compounds with the content of less than 0.5 , and the weighted ppm from the end of the tower.-Then, it is guided toward the naphtha purification unit. The reactor of this process is from the fixed bed type and usually, the feed flow in the interior of them is from the top to bottom, but sometimes it is used from the flow of bottom too high for the mixture of liquid and gas []․

\section{Octanizer (OCT) and Catalytic Continuous} Reforming units (CCR)

The goal of the Catalytic Reforming (OCT \& CCR) Unit is to produce clean and refined feed for the supply of Octane and Isomerization units [9]. The feeds of these units should have the lowest amount of pollutants such as sulphur, nitrogen, water, halogens, diolefins, olefins, arsenic, mercury and other metals, so that the efficiency of the lower units, especially the catalyst, is not affected by these units [1].

All of these cuts can have different levels of superpollution, which is catalytic converting, isomerization catalytic converters, and therefore hydrogen refining operations are essential.

The process of CCR is carried out in a reactor in the presence of a nickel-molybdenum bimetallic catalyst and in the presence of hydrogen. The temperature is relatively high $\left(270{ }^{\circ} \mathrm{C}\right.$, the temperature should be more than $250{ }^{\circ} \mathrm{C}$ which reaction would be started) required for the process to be performed. After chemical reactions, naphtha is subjected to buckling operations to separate hydrocarbon and gas components including hydrogen sulphides $\mathrm{H}_{2} \mathrm{~S}$ and water [11]].

Then, the oil cut in the separating tower (Splitter tower) is divided into two distinct sections for feeding the isomerization unit (Light Naphtha) and the Octanizer unit (Heavy Naphtha).

Surprisingly the high efficiency of the octane units and isomerization depends greatly on the efficiency and efficiency of the naphtha purification unit. The maximum limit for sulphur and nitrogen contamination in the refined feed unit is $0.5 \mathrm{ppm}$ and the final limit of contamination such as lead, copper, silica, nickel, chromium is less than ppb 10. 


\section{The system troubleshooting}

The main concern in this part is the passing of sulfur from the naphtha purification unit and the entrance of it into Octanizer and isomerization units. One of the most fundamental proceedings is the consignation of the separator and stripper towers' products toward the reservoirs. In this mood, the feed of the reformer and isomerization units is provided through reservoirs (fig 1). The beneficiary should ensure that the existent feed in the reservoirs and its linked routes are without water. In the absence of certainty, it is recommended that the feed of the reformer unit be reduced, or even the downstream units are removed from the service [12].

\section{The Model of the becoming deactivation of the} catalyst at constant temperature and output constant octane

If $t(a)$ is considered as the rate of catalyst activity at time $\mathrm{t}$

$$
a(t)=\frac{r_{a}(t)}{r_{a}(0)}
$$

In this equation, $r_{a}(t)$ is the reaction speed at time $t$ and $r_{a}(0)$ is the reaction speed at the start of the reaction with the fresh catalyst $(a=1)$.

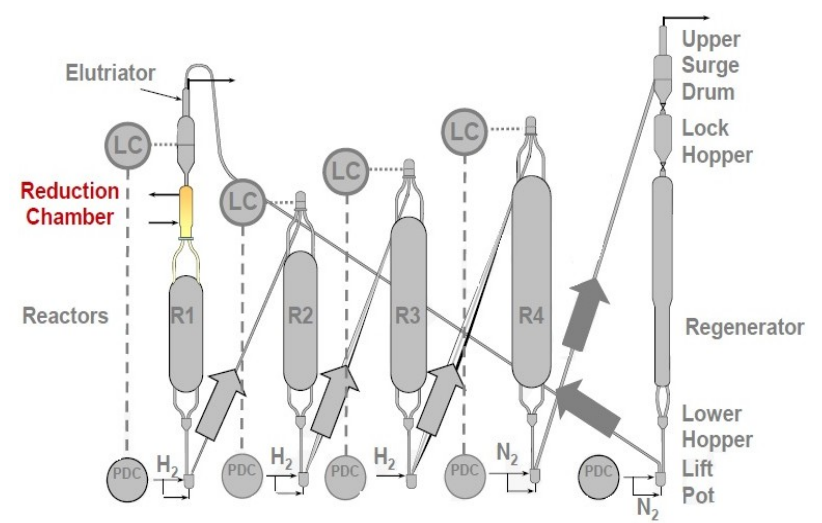

Fig 1: Schematic of Catalytic Continuous Reforming Unit
If the total speed of the reaction is considered at the form of the multiplication of the three sentences, the first contains the temperature dependence, the second representing the catalyst activity drop and the third is the concentration dependence according to the conversion degree $\left(X_{a}\right)$, because the temperature is constant, we have:

$r_{a}=-k_{0} \exp \left[\frac{-E_{A}}{R T}\right]$ af $\left(X_{A}\right)=-k^{\prime} a f\left(x_{A}\right)$

We use the following equation for illustration of the becoming deactivation rate of the catalyst:

$$
-\frac{d_{a}}{d_{t}}=k_{d 0} \exp \left[\frac{-E_{D}}{R T}\right] g\left(X_{A}\right) a^{n}
$$

In this equation, $\mathrm{k}_{\mathrm{d} 0}$ and $\mathrm{E}_{\mathrm{D}}$ are the constant parameters of the becoming deactivation rate and $g$ $\left(\mathrm{X}_{\mathrm{A}}\right)$ representing the concentration dependence in the activity rate equation and $n$ is the degree of the becoming deactivation rate [13]. At constant temperature and constant conversion rate, the becoming deactivation equation is summarized as follows:

$-\frac{d_{a}}{d_{t}}=k_{d 0} \exp \left[\frac{-E_{D}}{R T}\right] g\left(X_{A}\right) a^{n}=k_{d}^{\prime} a^{n}$

\section{Temperature changes with catalyst lifetime}

Industrial units, usually in order to compensate for the catalyst activity decline, try to control the quality of the product with increasing the temperature of the entrance feed instead of reducing the passing rate of the feed from the catalyst (LHSV) because reducing the amount of the product in order to control its quality isn't desirable and economical. 
Thus, one process of increasing temperature in the production process is observed simultaneously with the decrease of catalyst activity [14].

Increasing the rate of temperature is faced with limitations that determine the lifetime of the catalyst, including the thermic limitation of the reactor and the involved equipment in the process, changing the catalyst base construction, changing the distribution way of active elements on the catalyst (sintering), and also the high cost of the temperature supplying. Ending the catalyst life period, depending on the type of catalyst, the rate of price and also the possibility of revival, take action to its replacement or revival.

The following equation expresses the reality of the need to the temperature increase in order to compensation for the catalyst activity drop by connecting the catalyst activity to the function from the operating temperature. The conditions required for using the below equation are the product constant quality (constant conversion) and also being constant the feed rate (LHSV). The following relevance is being resulted from the equation (2) in constant conversion:

$$
k(T) a(t)=k\left(T_{0}\right)
$$

Wherein $\mathrm{T}_{0}$ is the used absolute temperature at the beginning of the utilization of the catalyst and $\mathrm{T}$ is the temperature to be used at time $t$ till it compensates the catalyst activity drop with the speed constant increase.

By placing the equivalent of the temperature function from equation 2 , the above equation is as follows:

$$
\begin{aligned}
& a(t) \exp \left[\frac{-E_{A}}{R T}\right]=\exp \left[\frac{-E_{A}}{R T_{0}}\right] \\
& a(t)=\exp \left[\frac{-E_{A}}{R}\left(\frac{1}{T_{0}}-\frac{1}{T}\right)\right] \\
& \frac{1}{T}=\frac{R}{E_{A}} \ln a+\frac{1}{T_{0}}
\end{aligned}
$$

By integration of the above equation, we have:

$$
t=\frac{E_{A}\left\{1-\exp \left[\left[\frac{E_{D}-n E_{A}+E_{A}}{R \cdot\left[\frac{1}{T}-\frac{1}{T_{o}}\right]}\right]\right]\right\}}{k_{d 0} \exp \left[\frac{-E_{D}}{R T_{0}}\right] \cdot\left[E_{D}-n E_{A}+E_{A}\right]}
$$

To summarize the above equation, we use two parameters $\mathrm{B}, \mathrm{A}$, which are defined as follows:

$$
\begin{aligned}
& t=A\left[1-\exp \left(B\left(\frac{1}{T}-\frac{1}{T_{0}}\right)\right)\right] \\
& A=\frac{\frac{E_{A}}{\left(E_{D}-n E_{A}+E_{A}\right)}}{k_{d 0}} \\
& B=\frac{E_{D}-n E_{A}+E_{A}}{R}
\end{aligned}
$$

By solving the equation for operating temperature, we have:

$$
T=\left[\frac{1}{T_{0}}+\frac{1}{B} \ln \left(1-\frac{t}{A}\right]^{-1}\right.
$$

The equation (13) shows the thermic connection (T) which must be used with the passage of time $(\mathrm{t})$ in order to compensate for the catalyst activity drop. 


\section{Results and Discussion}

Regarding the modeling and the review of the obtained results, it can be observed that the amount of pressure drop in the thermal inverters is decreased significantly and the pressure is increased in the high-pressure separator container and at the entrance compressor of the cyclical gas. Therefore, the output pressure and the amount of cyclical gas flow (the ratio amount of hydrogen to hydrocarbon in the reactor) could be adjusted in the appropriate values. Also, the amount of thermal load will become more in the boiler of the stripper tower. The amounts of hydrogen sulfide, ammonia, and water haven't so changed in the output of the unit. Economically, also, this plan didn't have much-fixed cost.

\section{Examination the Effect of Capacity Change of} Naphtha Catalytic Conversion Unit on the Gasoline Octane Number and the Amount of Coke Formed on the Catalyst

This scenario has been investigated in terms of constant input temperature to the reactors at $525^{\circ} \mathrm{C}$ and the constant rate of mass gas flow of 22 ton/hr with $90 \%$ purity and the constant mass flow of catalyst for $800 \mathrm{~kg} / \mathrm{hr}$. Before starting, the gas returned flow must be regulated and recorded with the definition of logical function $22 \mathrm{ton} / \mathrm{hr}$ in all conditions. In this trial, the heavy purificated Naphtha mass flow of catalytic conversion unit input feed with continuous revival has been considered as an independent variable for the unit capacity that will be changed in the range of 90000 to 170000 $\mathrm{kg} / \mathrm{hr}$.
The amount of produced gasoline octane number and the amount of coke formed percentage on the catalyst surface are also independent variables. It should be noted that the amount of coke formed percentage allowed range on the catalyst surface is based on the capacity of coke unit of catalyst resuscitation ranging from 3-7\%.

This range is a constraining factor in the operational condition for the amount of coke allowed. As can be seen, by increasing the catalyst conversion unit capacity, the gasoline octane number conversion unit will be decreased and the amount of coke formed percentage on catalyst surface unit will be increased. But, in this variation of unit capacity, the percentage of coke formed is within the permitted range [15].

\section{Investigation the Input Temperature of Catalytic} Conversion Unit Reactors Efficiency on Octane Number and the amount of Coke Formed on the Catalyst

Due to the importance of the input temperature to the reactors in the catalyst conversion process, sensitivity analysis was performed on changing the input temperature to the reactors on the octane number and the amount of coke production (Fig. 2).

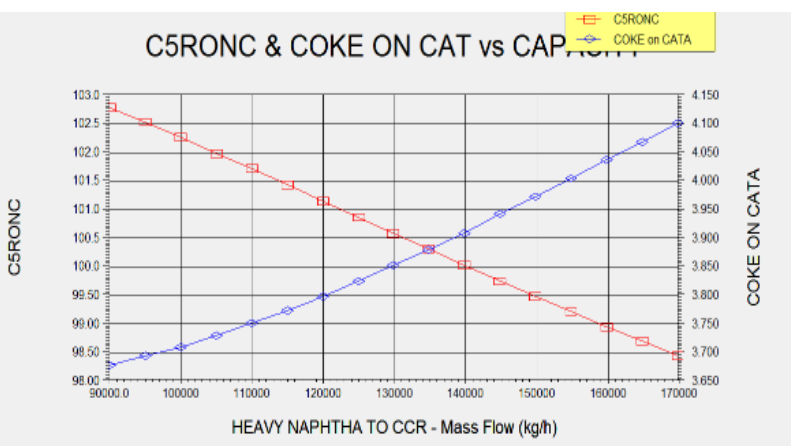

Fig. 2: Effect of the catalytic conversion unit capacity changes on gasoline octane number and the amount of coke formed percentage 
This state is examined at a constant capacity $150000 \mathrm{~kg} / \mathrm{hr}$ equivalent to 34000 barrels per day of purificated heavy Naphtha feed, which is the catalytic conversion unit of Naphtha nominal capacity and a constant mass flow rate of 22 ton/hr of hydrogen gas, and the mass constant flow of catalyst equivalent to $800 \mathrm{~kg} / \mathrm{hr}$. The reactors input temperature as a most important factors on octane number has been considered as an independent variable and also, gasoline product octane number and the amount of coke formed percentage on the catalyst surface as the dependent variable.

One of the important results of above figure is that the maximum permitted temperature of reactors input is $550^{\circ} \mathrm{C}$.

At warmer temperatures, positive dehydrogenation reactions tend to be more likely to negative hydrocracking reactions and their octane number not only changes but also decreases. As it is clear, the gasoline octane number will be increased by increasing the reactors temperature and the amount of coke formed, too. The slope of this coke formation increases dramatically at $520^{\circ} \mathrm{C}$, which is problematic, and is the limiting factor for temperature rise. The main desirable and effective reactions on octane number rise are endothermic process such as dehydrogenation of naphthenes, isomerization of paraffin's and naphthenes and carbonization of paraffin's by dehydrogenation and will be intensify by temperature increasing and pressure decreasing. Also, velocity of these reactions will kinematic be increased by temperature increasing.
As shown in Fig. 4, the activation energy of the reactions is related to the gradient of the diagram. The greater the gradient of the graph, the higher the activation energy and consequently, the increase in temperature will have a greater impact on the speed of the reaction such as carbonization of paraffin's which have high activation energy (about 35 $\mathrm{kg} / \mathrm{mole}$ ) then temperature will increase this reaction rate. Hydrocracking reactions and coke formation have higher activation energy (35 and 45 $\mathrm{kg} / \mathrm{mole}$ ). The velocity of these undesirable reactions is noticeable by temperature rise.

According to the literature, the steep slope of coke increasing seems to be logical as the temperature rises.

According to the obtained results and maximum allowed coke and desirable octane number in this study, the optimal input temperature of the catalytic conversion reactors at these conditions and capacity is obtained $150000 \mathrm{~kg} / \mathrm{hr}$ and in the range of 525 $530{ }^{\circ} \mathrm{C}[\underline{16}]$.

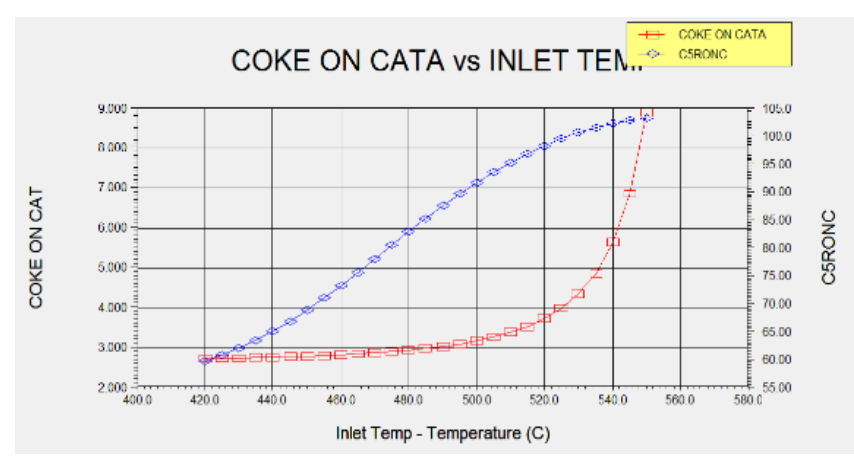

Fig. 3: Effect of input temperature changing of the catalytic conversion unit on gasoline octane number and the amount of coke formed percentage on catalyst 
The Reactor Input Temperature and Catalyst Velocity Flow in Different Capacities must be how the Octane Number will be a Constant Rate 95 and the amount of Coke Formation in all Conditions 3.5\%

One of the most functional and practical issues that is required for using of catalytic conversion unit of continuous resuscitation is this scenario. It is mainly due to various reasons and conditions that the unit operating in different capacities will have to produce gasoline with the required octane number. On the other hand, due to the settings and limitations of the coke and catalyst reduction, the percentage of coke formed should also be fixed and specified. The results of this study can play an effective role in controlling and right and proper regulating of mentioned operational unit. The fixed condition of this scenario is the coke formed percentage equivalent to 3.5 percent and product gasoline octane number 99 and the rate of returned hydrogen gas mass flow with a purity of 90 percent has been considered 22 ton per hour. In this study the purificated heavy Naphtha mass flow input feed of catalytic conversion unit with continuous resuscitation has been considered as an independent variable for unit capacity which is changed in a range from 90000 to $170000 \mathrm{~kg} / \mathrm{hr}$. The finding values of dependent variables which are the main purpose of this issue to regulate and control the operational unit, are reactors input temperature and rate of catalyst mass flow. The amount of coke formed percentage depends on different parameters and factors such as unit capacity, reactors input temperature, velocity of catalyst circulation flow, purity of returned hydrogen gas, portion of hydrogen to hydrocarbons and input reactors pressure. Among the mentioned factors, the most effective factor in this scenario can be applied to regulate and stabilize the coke formed percentage by changing on it, is the velocity of continuous catalytic conversion unit. (Fig. 4). The variable compliance of coke formation rate is an inverse ratio in relation to the parameter catalyst circulation flow. The higher the catalyst circulation flow rate, the lower the percentage of formed coke but due to increasing the velocity of the catalyst circulation flow, the possibility of the erosion and decrease of the useful life of the catalyst will be decreased by erosion increasing. By defining a flow as input values of the fluctuating flow of a catalyst and moving it to a spreadsheet and using the ADJ logical operator in different conditions, after the effects of the reactor and reactor gas intake and input temperature variations and the returning hydrogen gas, with a mass flow regulation of the catalyst It can be used to stabilize $3.5 \%$ of the coke formed on the catalyst surface. It should be noted that the design capacity of the catalytic resuscitation system is $58 \mathrm{~kg}$ of coke at an hour with a catalyst flow rate of $820 \mathrm{~kg}$ per hour. According to the results, it is shown that in capacities above 145000 $\mathrm{kg} / \mathrm{hr}$ the required flow of catalyst to stabilize $3.5 \%$ of the coke will be higher than the optimal design, The shape of the desire to operate in the optimal design conditions range with changing other process conditions, such as increasing the percentage of coke production to reduce the catalyst flow, or increasing the purity of the reversed hydrogen gas or increasing the amount of hydrogen gas returned can be brought into optimal conditions. 
Of course, in the information gathered from the unit control values, floods above $1200 \mathrm{~kg} / \mathrm{hr}$ can also be seen for the amount of catalyst flow.

\section{Investigation the Effect of Catalytic Flow}

Fluctuation Changes on the Percentage of Coke

\section{Composition Formed on the Catalyst}

Considering the importance of controlling the amount of coke formed at a nominal capacity of $150,000 \mathrm{~kg} / \mathrm{hr}$ (mainly the capacity of the continuous catalytic conversion unit of the gasification complex of the refinery is being exploited in this capacity), and in order to complete the information required in the previous scenario, the need for review the effect of the catalyst flow on the amount of coke formed in this capacity and in terms of the amount of returnable hydrogen gas equivalent to 22 ton/hr with a purity of $90 \%$ and a constant temperature of $525{ }^{\circ} \mathrm{C}$ input reactors seemed essential.

The proper flow rate of the catalyst is 600 to 1200 kilograms per hour. Higher fluxes result in more erosion and reduced useful life of the catalyst [17].

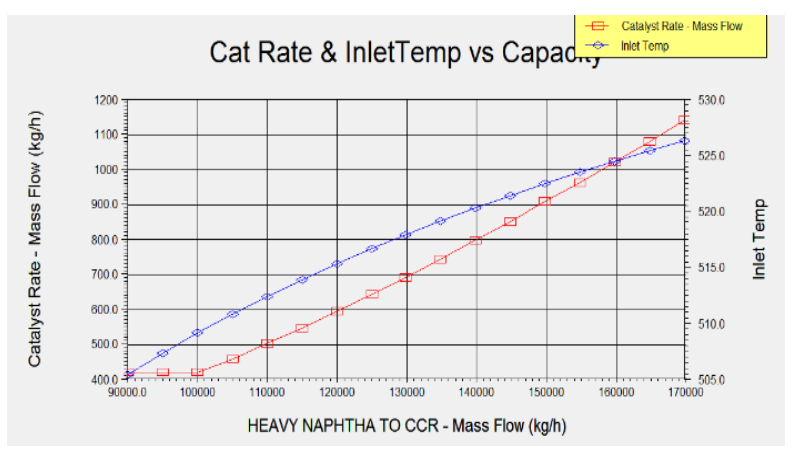

Figure 4: The graph of the results of setting the reactor input temperature and the catalyst flow rate at different capacities such that the octane number, the steady state 99 , and the percentage of coke formation in all conditions were $3.5 \%$

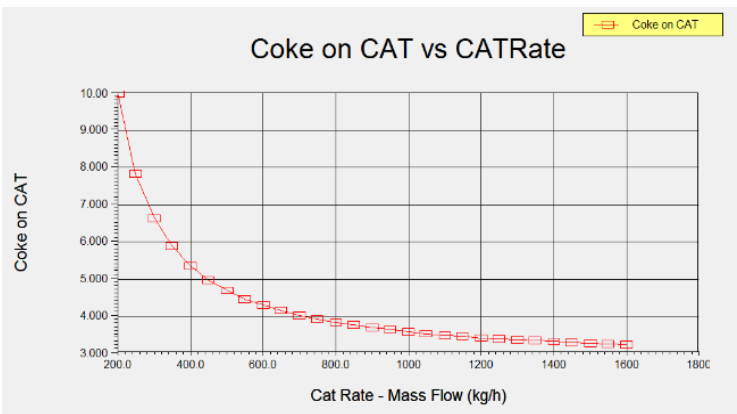

Fig. 5: Results of the study of the effect of the fluctuation of the catalytic circulation on the percentage of coke formed on the catalyst at a constant capacity of 83,000 barrels per day

In this study, the independent variable is a mass flow rate of a catalyst, defined by the definition of a current and its mass flow rate as the input of this test, and the percentage of coke as dependent variable (Fig. 5).

\section{Comprehensive Review of the Effect of Reactor} Input Temperature Changes and Unit Capacity on

\section{Gasoline Octane Number}

As mentioned above, the most important factors and parameters affecting the gasoline product octane number are the input temperature of the reactors and the capacity of the catalytic converter unit. Therefore, considering the importance of these factors and their widespread use in different operating conditions of the operating unit, the study and preparation of information and complete and comprehensive results in this regard for the use of staff at the time of occurrence of each various operating conditions seems necessary and essential. This study was carried out in a fixed mass of 200 $\mathrm{gr} / \mathrm{hr}$ with a purity of $90 \%$ and a stabilization of $3.5 \%$ of the coke formed on the catalyst [18]. The 
main difference between this experiment and the preceding ones is the number and method of introducing and using the variables and their display. In previous modes, an independent variable was always determined and used, while in this study, two independent variables were used to observe the variations of a dependent variable. Thus, the results chart of this study is obtained in several pages in space.

In this experiment, the capacity of a catalytic conversion unit based on the mass flow rate of the heavy naphtha refined feedstock, and the reactor input temperature is determined as an independent variable, and the octane number is a dependent variable. The total points or stages obtained in this study are 493 points calculated. This chart is available through the software of Petrochem, the ability to move and rotate for access, and the ability to view the results more accurately.

As can be seen from the results, the optimum input temperature of the reactors is $525^{\circ} \mathrm{C}$, because in addition to the ability to produce gasoline, the octane number 95 for nominal capacity of 30,000 b/day, a catalytic conversion, has a greater range of capacities various applications are used to produce 95 octane gasoline.

For a maximum capacity of 170 ton/hr, (Fig. 6), this temperature has the ability to produce gasoline with an octane value of 6/98, which can be made by applying minor changes such as increasing the temperature of the stabilizing tower Catalytic converter unit or increase the ratio of hydrogen to hydrocarbon or a slight increase in inlet pressure The reactors achieved petrol with an octane number of 95 .

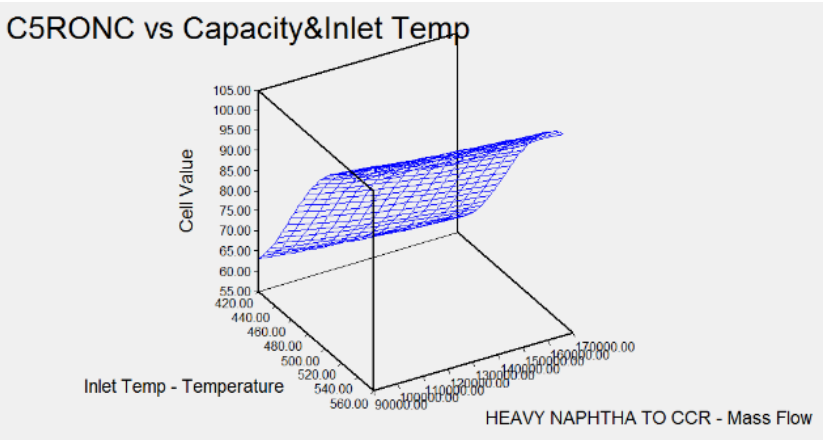

Fig. 6: Results of the simultaneous effect of reactor input temperature changes and unit capacity on gasoline octane number.

\section{Conclusion}

One of the most important process in refineries is Naphtha catalytic conversion. In this process, gasoline with high octane number produce in the petrochemical complexes of precious aromatics such as benzene, toluene and xylene. Due to the importance of fuel and its more production of initial oil materials and the optimization possibility and catalytic reactor performance improvement in order to increasing the quality and quantity of products, the necessity of simulation and investigation the involved parameters and its performance improvement will be necessary. This process contains three numbers radial flow reactors, furnace, a separator tank, some thermal conversion and a compressor which has been done more than 300 reactions in these reactors that should be use the presented kinetics models for simulation. In the refinery, the input temperature of the three reactors is same that the catalyst will gradually be inactive, the reactors input temperature will increase with respect to product quality analysis. Also, the input features feed changes and its flow rate fluctuations 
will effect on products distribution and octane number then will make it unstable [19-24].

It should be noted that if the percentage of compounds and the values of distilled feed of purificated Naphtha unit changed, the recommended operational values and unit process conditions will be changed.

The naphtha purification process is one of the processes of hydrogenous purification in petrochemical complexes and refineries that by removing sulfur, nitrogen, oxygen, metals, and halogens from the entrance heavy naphtha feed to the catalytic conversion unit, it makes possible the production of gasoline with the least pollutants of the environment in addition to protecting the catalyst from toxins and the precocious deactivation. In this research, increasing the capacity of the naphtha purification unit of one of the country's from 11,000 barrels to 19,000 barrels per day without the outbreak of problems such as increasing the pressure drop in the aerial and evaporative coolers in the separation part, reducing the exhaust

\section{References:}

[1] D. Guillaume, E. Valéry, J. Verstraete, K. Surla, P. Galtier and D. Schweich, Single event kinetic modelling without explicit generation of large networks: application to hydrocracking of long paraffins. Oil \& Gas Science and TechnologyRevue d'IFP Energies nouvelles, 66 (2011) 399-422.

[2] A. Samimi, S. Zarinabadi, A.H. Shahbazi Kootenaei, A. Azimi and M. Mirzaei, Study of Operational Conditions in Octanizer and Hydro-Treating Units in Oil Refinery Company. Journal of Chemical Reviews, 1 (2019) 164-182.

[3] A.J. Amiri and M. Farhadi, Numerical investigation of a single feedback loop oscillator with two outlet channels. Chemical Engineering Research and Design, 150 (2019) 206-217. pressure of the cyclical gas compressor and reducing the catalyst life, had been investigated.

In this research, operating conditions have been investigated that indicates the increase of the petrochemical feed with the design capacity of 71,000 barrels per day, to the amount of 83,000 barrels per day. The results indicate that with increasing feed, the entrance temperature and pressure to the unit reactor should be increased. With regards to all the above conditions, it is proved that increasing the feed is an acceptable action according to the resulting profit from the sale of the products.

\section{Conflict of interests}

The authors declare that there is no conflict of interests regarding the publication of this paper.

[4] A. Samimi, S. Zarinabadi, A.H. Shahbazi Kootenaei, A. Azimi and M. Mirzaei, Optimization of the naphtha hydro treating unit (NHT) in order to increase feed in the refinery. Iranian Chemical Communication, (2019) 121-132.

[5] K. Surla, D. Guillaume, J. Verstraete and P. Galtier, Kinetic modeling using the single-event methodology: application to the isomerization of light paraffins. Oil \& Gas Science and Technology-Revue d'IFP Energies nouvelles, 66 (2011) 343-365.

[6] H. Cochegrue, P. Gauthier, J. Verstraete, K. Surla, D. Guillaume, P. Galtier and J. Barbier, Reduction of single event kinetic models by rigorous relumping: application to catalytic reforming. Oil \& Gas Science and Technology-Revue d'IFP Energies nouvelles, 66 (2011) 367-397. 
[7] T. Gueddar and V. Dua, Disaggregation-aggregation based model reduction for refinery-wide optimization. Computers \& chemical engineering, 35 (2011) 1838-1856.

[8] M. Gyngazova, N. Chekantsev, M. Korolenko, E. Ivanchina and A. Kravtsov, Optimizing the catalyst circulation ratio in a reformer with a moving bed via a combination of real and computational experiments. Catalysis in Industry, 4 (2012) 284-291.

[9] D. Iranshahi, M. Karimi, S. Amiri, M. Jafari, R. Rafiei and M.R. Rahimpour, Modeling of naphtha reforming unit applying detailed description of kinetic in continuous catalytic regeneration process. Chemical Engineering Research and Design, 92 (2014) 1704-1727.

[10] A. Samimi, S. Zarinabadi, S. Kotanaei, A. Hossein, A. Azimi and M. Mirzaei, Use of data mining in the corrosion classification of pipelines in catalytic reforming units (CRU). Eurasian Chemical Communications, 1 (2019) 681-691.

[11] R. Ding, P. Zhang, M. Seredych and T.J. Bandosz, Removal of antibiotics from water using sewage sludge-and waste oil sludge-derived adsorbents. Water research, 46 (2012) 4081-4090.

[12] L.S. De Lima, M.D.M. Araujo, S.P. Quináia, D.W. Migliorine and J.R. Garcia, Adsorption modeling of $\mathrm{Cr}, \mathrm{Cd}$ and $\mathrm{Cu}$ on activated carbon of different origins by using fractional factorial design. Chemical engineering journal, 166 (2011) 881889.

[13] C. Lu, S. Xu and C. Liu, The role of K2CO3 during the chemical activation of petroleum coke with KOH. Journal of Analytical and Applied Pyrolysis, 87 (2010) 282-287.

[14] S.V. Mayani, V.J. Mayani, S.-K. Park and S.W. Kim, Synthesis and characterization of metal incorporated composite carbon materials from pyrolysis fuel oil. Materials Letters, 82 (2012) 120-123.

[15] A. Samimi, S. Zarinabadi, A.H. Shahbazi Kootenaei, A. Azimi and M. Mirzaei, Considering different kinds of gasoline unit catalysts. Journal of Medicinal and Chemical Sciences, 3 (2020) 7994.

[16] S.M. Alwahabi and G.F. Froment, Single event kinetic modeling of the methanol-to-olefins process on SAPO-34. Industrial \& engineering chemistry research, 43 (2004) 5098-5111.

[17] B. Ducourty, G. Szabo, J. Dath, J. Gilson, J. Goupil and D. Cornet, $\mathrm{Pt} / \mathrm{Al} 2 \mathrm{O} 3-\mathrm{Cl}$ catalysts derived from ethylaluminumdichloride: Activity and stability in hydroisomerization of C6 alkanes. Applied Catalysis A: General, 269 (2004) 203214.
[18] A. Galadima, J. Anderson and R. Wells, Solid acid catalysts in heterogeneous n-alkanes hydroisomerisation for increasing octane number of gasoline. Science World Journal, 4 (2009) 15-22.

[19] M. Gyngazova, A. Kravtsov, E.D. Ivanchina, M. Korolenko and D. Uvarkina, Kinetic model of the catalytic reforming of gasolines in movingbed reactors. Catalysis in industry, 2 (2010) 374-380.

[20] S. Jenner and A.J. Lamadrid, Shale gas vs. coal: Policy implications from environmental impact comparisons of shale gas, conventional gas, and coal on air, water, and land in the United States. Energy Policy, 53 (2013) 442-453.

[21] J. Peischl, A. Karion, C. Sweeney, E. Kort, M. Smith, A. Brandt, T. Yeskoo, K. Aikin, S. Conley and A. Gvakharia, Quantifying atmospheric methane emissions from oil and natural gas production in the Bakken shale region of North Dakota. Journal of Geophysical Research: Atmospheres, 121 (2016) 61016111.

[22] D.R. Lyon, R.n.A. Alvarez, D. Zavala-Araiza, A.R. Brandt, R.B. Jackson and S.P. Hamburg, Aerial surveys of elevated hydrocarbon emissions from oil and gas production sites. Environmental science \& technology, 50 (2016) 4877-4886.

[23] C.E. Kemp, A.P. Ravikumar and A.R. Brandt, Comparing natural gas leakage detection technologies using an open-source "virtual gas field" simulator. Environmental science \& technology, 50 (2016) 4546-4553.

[24] J. Kuo, T.C. Hicks, B. Drake and T.F. Chan, Estimation of methane emission from California natural gas industry. Journal of the Air \& Waste Management Association, 65 (2015) 844-855. 